\title{
ORIGINAL
}

\section{Determinants of self-reported unacceptable outcome of intensive care treatment 1 year after discharge}

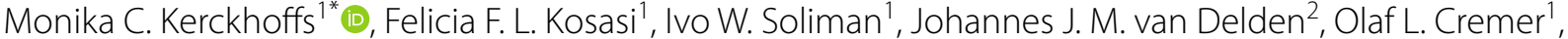 \\ Dylan W. de Lange ${ }^{1}$, Arjen J. C. Slooter ${ }^{1}$, Jozef Kesecioglu ${ }^{1}$ and Diederik van Dijk ${ }^{1}$
}

(c) 2019 The Author(s)

\begin{abstract}
Purpose: Survivors of critical illness often suffer from reduced health-related quality of life (HRQoL) due to long-term physical, cognitive, and mental health problems, also known as post-intensive care syndrome (PICS). Some intensive care unit (ICU) survivors even consider their state of health unacceptable. The aim of this study was to investigate the determinants of self-reported unacceptable outcome of ICU treatment.
\end{abstract}

Methods: Patients who were admitted to the ICU for at least $48 \mathrm{~h}$ and survived the first year after discharge completed validated questionnaires on overall HRQOL and the components of PICS and stated whether they considered their current state of health an acceptable outcome of ICU treatment. The effects of overall HRQoL and components of PICS on unacceptable outcome were studied using multiple logistic regression analysis.

Results: Of 1453 patients, 67 (5\%) reported their health state an unacceptable outcome of ICU treatment. These patients had a lower score on overall HRQoL (EQ-5D-index value of 0.57 vs. $0.81 ; p<0.001$ ), but we could not determine a cutoff value of the EQ-5D-index value that reliably identified unacceptable outcome. In the multivariate analysis, only the hospital anxiety and depression scale was significantly associated with an unacceptable outcome (OR 2.06, 99\% Cl 1.18-3.61).

Conclusions: Although there is a strong association between low overall HRQOL and self-reported unacceptable outcome of ICU treatment, patients with low overall HRQoL may still consider their outcome acceptable. The mental component of PICS, but not the physical and cognitive component, is strongly associated with self-reported unacceptable outcome.

Keywords: Health-related quality of life, Long-term outcome, Post-intensive care syndrome, Patient-reported outcome measure, Ethics

\footnotetext{
*Correspondence: m.c.kerckhoffs-2@umcutrecht.nl

${ }^{1}$ Department of Intensive Care Medicine, University Medical Center

Utrecht, Utrecht University, Mail Stop F06.149, P.O. Box 85500, 3508

GA Utrecht, The Netherlands

Full author information is available at the end of the article
}

\section{国 Springer}




\section{Introduction}

The primary aim of intensive care medicine used to be saving lives. However, intensive care unit (ICU) survival may come at a price: many patients suffer from post-intensive care syndrome (PICS) comprising ICUrelated limitations in physical, cognitive, and mental functioning [1]. With the recognition of these sequelae of ICU treatment, the focus in outcome research shifted more and more from hospital survival towards longterm survival, health-related quality of life (HRQoL), and functional outcomes [2-8].

Functional outcomes are usually measured with standardized and validated questionnaires, filled in by the patient without interpretation by a clinician [9]. These so-called patient-reported outcome measures (PROMs) exist for overall HRQoL as well as for the components of PICS and there is broad consensus to use these in long-term outcome studies [10]. Although both patients and researchers agree on the importance of measuring these outcomes, evidence that supports the measurement quality of the various PROMs in ICU survivors specifically is limited [11]. Research that involved patients to define relevant outcomes revealed that there is no PROM that covers all relevant aspects of a good outcome $[12,13]$. In addition, not all symptoms that impact well-being are included in currently used PROMs [14].

Some patients state that they do not want to survive critical illness if it results in a poor quality of life, but it appears very difficult to uniformly define poor outcome. There is hardly any evidence that helps to classify overall HRQoL values into acceptable or unacceptable outcome, and researchers arbitrary define poor outcome when conducting long-term outcome studies in ICU patients [15]. In addition, for ICU survivors reporting a lower quality of life, it is not fully known how the various components of PICS contribute to a lower quality of life or an unacceptable outcome.

The aim of this study was to investigate the effect of overall HRQoL and of the components of PICS on the risk of a self-reported unacceptable outcome of ICU treatment.

\section{Methods}

\section{Study design and setting}

This cohort study was conducted in the ICU of the University Medical Center Utrecht, the Netherlands. This is a tertiary, adult, mixed ICU with 2200 admissions per annum.

\section{Take-home message}

Self-reported unacceptable outcome in survivors of critical illness is associated with poor HRQoL and mostly explained by the mental component of PICS and not by the physical or cognitive impairments.

All consecutive patients admitted to the ICU between 2010 (start of prospective data collection) and 2016 were eligible.

\section{Participants}

Patients who had been admitted to the ICU for at least $48 \mathrm{~h}$ and who were still alive 1 year after ICU discharge were eligible. If case of readmission, data from the first admission was used. Patients were excluded when under 16 years of age, without a known address, not traceable through the municipal registry, or when they opted out of participation in scientific studies. The institutional review board of the University Medical Center Utrecht approved the study and waived the need for informed consent (UMC Utrecht IRB 10/006). One year after ICU discharge the Dutch municipal population register was consulted to identify and exclude deceased patients. A survey was subsequently sent by mail to all surviving patients.

\section{Variables}

Baseline characteristics are reported in Table 1.

The survey contained PROMs to evaluate overall HRQoL and physical, cognitive, and mental functioning (Table 2). These are the possible determinants of an unacceptable outcome:

1. Overall HRQoL measured by the EuroQol-5 dimension (EQ-5D-3L) [16, 17].

2. Physical functioning measured by the Barthel index [18].

3. Cognitive functioning measured by the cognitive failures questionnaire (CFQ) [19].

4. Depressive symptoms measured by the hospital anxiety and depression scale (HADS) [20].

5. Post-traumatic stress disorder symptoms measured by the impact of event scale (IES) [21].

The outcome measure of this study was disagreement with the statement "I consider my current condition an acceptable outcome of the ICU treatment." This was measured by including a question in the survey asking a response (agree/neutral/disagree) to this statement. 
Table 1 Baseline characteristics

\begin{tabular}{|c|c|c|c|c|c|}
\hline & Acceptable $(n=1073)$ & Neutral $(n=313)$ & Unacceptable $(n=67)$ & Total $(n=1453)$ & $p$ value \\
\hline Male gender & $710(66.2)$ & $187(59.7)$ & $37(55.2)$ & $934(64.3)$ & 0.032 \\
\hline Age at admission (years) & $60(49-70)$ & $59(50-69)$ & $55(44-67)$ & $59(49-70)$ & 0.265 \\
\hline Living in a nursing home & $36(3.4)$ & $29(9.3)$ & $7(10.4)$ & $72(5.0)$ & $<0.001^{*}$ \\
\hline ICU LOS (in days) & $5.06(3.16-9.42)$ & $5.52(3.07-9.84)$ & $5.03(2.96-10.59)$ & $5.10(3.08-9.61)$ & 0.865 \\
\hline Type of admission & & & & & 0.937 \\
\hline Elective surgery & $287(26.7)$ & $86(27.5)$ & $18(26.9)$ & $391(26.9)$ & \\
\hline Emergency surgery & $311(29.0)$ & $84(26.8)$ & $18(26.9)$ & $413(28.4)$ & \\
\hline Medical & $467(43.5)$ & $143(45.7)$ & $31(46.3)$ & $641(44.1)$ & \\
\hline Number of comorbidities & & & & & 0.855 \\
\hline 0 & $677(63.1)$ & $199(63.6)$ & $43(64.2)$ & $919(63.2)$ & \\
\hline 1 & $274(25.5)$ & $73(23.3)$ & $17(25.4)$ & $364(25.1)$ & \\
\hline 2 or more & $120(11.2)$ & $41(13.1)$ & $7(10.4)$ & $168(11.6)$ & \\
\hline APACHE score & $59.00(45-80)$ & $59.00(45-76)$ & $55(47-78)$ & $59(45-79)$ & 0.222 \\
\hline SOFA highest score & $13(8-17)$ & $11.5(7-16)$ & $12(6-16)$ & $12(8-16)$ & 0.013 \\
\hline $\mathrm{CWVH}$ & $108(10.1)$ & $33(10.5)$ & $9(13.4)$ & $150(10.3)$ & 0.682 \\
\hline
\end{tabular}

Baseline characteristics of patients who responded acceptable/neutral/unacceptable to the acceptable state of health question. Continuous data are presented as median (IQR). Categorical data are presented as $n(\%)$. Chi-square test was used for categorical data, one-way ANOVA for continuous data

ICU intensive care unit, IQR interquartile range, LOS length of stay, COPD chronic obstructive pulmonary disease, AIDS acquired immune deficiency syndrome, APACHE acute physiology and chronic health evaluation, SOFA sepsis-related organ failure assessment, CVVH continuous venovenous hemofiltration

${ }^{*} p<0.003$ was considered to be statistically significant

Table 2 Possible determinants of unacceptable outcome

\begin{tabular}{|c|c|c|c|c|c|}
\hline & Determinant & PROM & Measures & Scale & Interpretation \\
\hline 1 & Overall HRQoL $[16,17]$ & $\begin{array}{l}\text { EuroQoL EQ-5D (EQ-5D-3L) } \\
\text { index value }\end{array}$ & $\begin{array}{l}\text { Five dimensions: mobility, } \\
\text { self-care, usual activities, pain/ } \\
\text { discomfort, and mood }\end{array}$ & -0.3 to 1.0 & $\begin{array}{l}\text { Higher index values reflect a } \\
\text { better overall HRQoL }\end{array}$ \\
\hline 2 & Physical functioning [18] & Barthel index & $\begin{array}{l}\text { Degree of functional ability } \\
\text { and dependency concerning } \\
\text { activities of daily living }\end{array}$ & $0-20$ & $\begin{array}{l}\text { Higher scores reflect more } \\
\text { functional independence }\end{array}$ \\
\hline 3 & Cognitive functioning [19] & $\begin{array}{l}\text { Cognitive failures questionnaire } \\
\text { (CFQ) }\end{array}$ & $\begin{array}{l}\text { Cognitive functions in four } \\
\text { categories evaluated with } 25 \\
\text { items }\end{array}$ & $0-100$ & $\begin{array}{l}\text { Higher scores reflect more } \\
\text { cognitive failures }\end{array}$ \\
\hline 4 & Depressive symptoms [20] & $\begin{array}{l}\text { Hospital anxiety and depression } \\
\text { scale (HADS) }\end{array}$ & $\begin{array}{l}\text { Anxiety and depression levels. } \\
\text { Seven questions concern } \\
\text { anxiety and seven questions } \\
\text { concern depression }\end{array}$ & $\begin{array}{l}0-42 \text { (two } \\
\text { subscales } \\
0-21 \text { ) }\end{array}$ & $\begin{array}{l}\text { Higher scores reflect more } \\
\text { symptoms of anxiety and/or } \\
\text { depression }\end{array}$ \\
\hline 5 & $\begin{array}{l}\text { Post-traumatic stress dis- } \\
\text { order symptoms [21] }\end{array}$ & Impact of event scale (IES) & $\begin{array}{l}\text { Intrusion and avoidance on } \\
\text { subscales, evaluated with } 15 \\
\text { items }\end{array}$ & $0-75$ & $\begin{array}{l}\text { Higher scores reflect more post- } \\
\text { traumatic stress symptoms }\end{array}$ \\
\hline
\end{tabular}

PROM patient -reported outcome measure

\section{Data sources}

Baseline characteristics were collected by consulting the electronic patient record, the remainder by consulting the surveys. The participants were asked to fill in the survey themselves or to state if assistance was received. Data were entered in an electronic database by independent research assistants.

\section{Bias}

To reduce bias, patients received several reminders by mail and telephone. Multivariate analyses were applied to correct for known confounders.

\section{Study size}

The inclusion of five determinants in the multivariate logistic regression model required at least 50 cases (patients with unacceptable outcome) in the study. 
Recruitment stopped after 5.5 years when 67 cases and a total number of 1453 patients were included.

\section{Statistical methods}

Patients were divided into three groups according to their response to the acceptable outcome statement: (1) acceptable-patients responding with "agree," (2) neutral-patients responding with "neutral," (3) unacceptable-patients responding with "disagree." A baseline table was constructed to compare the three groups. Differences between the groups were studied using the appropriate tests (Chi-square test or Fisher's exact test for categorical data, one-way ANOVA for continuous data).

In order to analyze the association between the various PROMs and self-reported unacceptable outcome of ICU treatment, multiple logistic regression was performed. Since the undesirable outcome was unacceptable outcome, the other two groups were merged. To assess the effect of merging these groups, we performed a sensitivity analysis in which we combined the "neutral" respondents with the patients who reported an unacceptable outcome. In addition, we performed a multinomial regression analysis to assess the differences between the three groups.

The strength of the association between the PROMs and self-reported unacceptable outcome was analyzed using the odds ratios from multiple logistic regression models. Since each PROM is measured with a different questionnaire and uses different scales, the questionnaire scores were standardized by converting them into $\mathrm{z}$-scores for the multivariate analyses. The HRQoL and Barthel score were first inverted, so that higher z-scores implied worse outcomes for every PROM.

To correct for differences between the patient groups, we performed three multivariate logistic regression analyses. In the first logistic regression analysis, the effect of the various PROMs on acceptable outcome of ICU treatment was calculated with correction for demographic characteristics such as age, gender, and place of residence. In the second analysis, a correction for demographic and ICU characteristics was applied. ICU characteristics were type of admission, length of stay, comorbidities, APACHE score, highest SOFA score, and use of continuous venovenous hemofiltration $(\mathrm{CVVH})$. The APACHE score, SOFA score, and use of CVVH were chosen as indicators for severity of illness. Comorbidities were classified in three groups: no comorbidity, one comorbidity, and two or more comorbidities. Lastly, a third logistic regression analysis was performed to calculate the individual effect of each PROM by adjusting for the other PROMs in addition to the demographic characteristics and ICU characteristics. Because overall HRQoL, as measured in the EQ-5D, includes all the components of PICS, overall HRQoL was left out of the final analysis.

Since we calculated 19 different $p$ values for the comparison of the study outcomes, the significance level was modified using the Bonferroni correction to less than $0.003(0.05 / 19)$. The odds ratios (ORs) obtained with the logistic regression analyses are presented with 99 percent confidence intervals $(99 \% \mathrm{CI})$.

As post hoc analysis, the EQ-5D index values were analyzed to define a cutoff point in EQ-5D index values that indicates a self-reported unacceptable outcome of ICU treatment. A box plot and ROC curve were constructed to compare the distribution of EQ-5D index values in the two groups.

We also performed a post hoc logistic regression analysis to assess the association between each EQ-5D domain (mobility, self-care, usual activities, pain, mood) and unacceptable outcome of ICU treatment.

\section{Results \\ Participants}

A flowchart of the study population enrollment is presented in Fig. 1. During the 6-year study period 2294 patients were admitted for at least $48 \mathrm{~h}$ and survived at least 1 year. The survey was returned by 1632 patients (71\%). Complete responders $(n=1453,89 \%)$ were defined as patients who answered the question about acceptable outcome and all the questions of the EQ-5D.

Within the complete responders, 1073 patients (74\%) agreed with the statement that their current condition is an acceptable outcome of ICU treatment, $313(22 \%)$ responded neutral, and 67 patients $(5 \%)$ disagreed with the statement.

Characteristics of the participants are presented in Table 1. Gender, place of residence, and highest SOFA score differed significantly across the three groups.

\section{Outcome data}

Table 3 shows the distribution of the various PROMS for the three groups of respondents. The ICU survivors who reported an unacceptable outcome of ICU treatment reported an EQ-5D index value of 0.57 (99\% CI 0.17 0.78 ) compared to an EQ-5D index value of 0.81 (99\% CI $0.69-1.00)$ in ICU survivors reporting an acceptable or neutral outcome.

\section{Main results}

Table 4 shows the analysis of patients who reported an unacceptable outcome of ICU treatment, compared to patients who responded neutral or acceptable. The unadjusted odds ratios showed a significant association between a more unfavorable value on the EQ-5D (OR $2.09,99 \%$ CI 1.62-2.69), on the HADS (OR 2.20, 99\% CI 


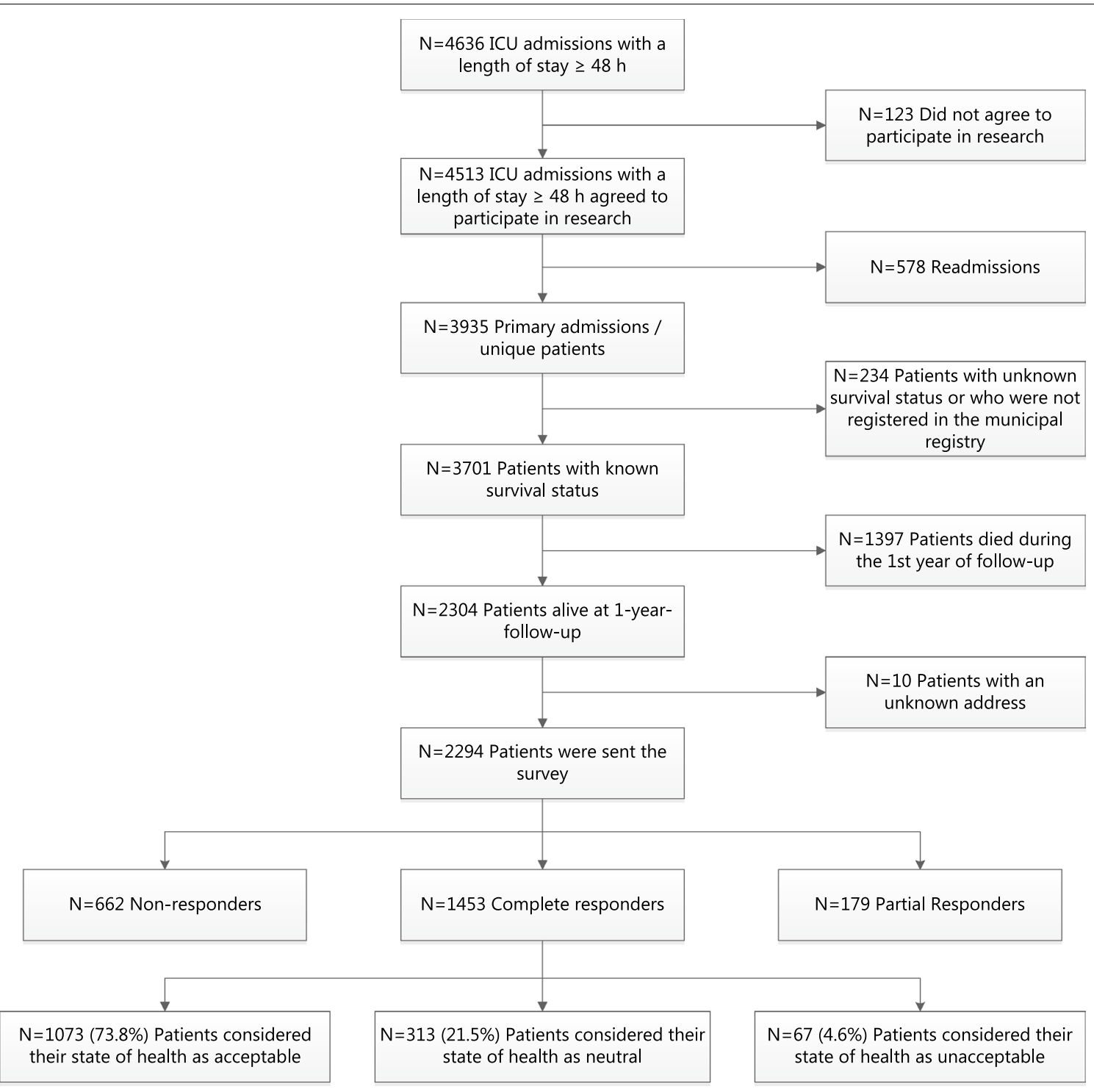

Fig. 1 Flowchart of the enrollment process. Flowchart depicting the enrollment process, reasons for exclusion, and follow-up of the enrolled patients. ICU intensive care unit

Table 3 Raw questionnaire scores related to self-reported outcome groups

\begin{tabular}{lcccc} 
& Unacceptable $(n=67)$ & Neutral $(n=313)$ & Acceptable $(n=1073)$ & $\begin{array}{c}\text { Neu- } \\
\text { tral+acceptable } \\
(n=1386)\end{array}$ \\
\hline EQ-5D & $0.57(0.17-0.78)$ & $0.77(0.43-0.86)$ & $0.84(0.72-1.00)$ & $0.81(0.69-1.00)$ \\
Barthel Index & $19(15.5-20)$ & $20(16-20)$ & $20(19-20)$ & $20(19-20)$ \\
CFQ & $27(12-41.3)$ & $23.5(11-36)$ & $20(10-30)$ & $21(11-32)$ \\
HADS & $18(12.5-24.5)$ & $14(10-19)$ & $11(8-15)$ & $11(8-16)$ \\
IES & $21(0-36.8)$ & $9(0-25)$ & $6(0-17)$ & $6(0-19)$ \\
\hline
\end{tabular}

Raw questionnaire scores of patients presented for the groups self-reporting their outcome as unacceptable, acceptable, neutral, and the combined acceptable plus neutral group. Data are presented as median (IQR)

IQR interquartile range, EQ-5D EuroQoL-5 dimension index value, CFQ cognitive failures questionnaire, HADS hospital anxiety and depression scale, IES impact of event scale 
Table 4 Association between questionnaire scores and self-reported unacceptable outcome

\begin{tabular}{|c|c|c|c|c|c|c|c|c|}
\hline & $\begin{array}{l}\text { OR unadjusted }(99 \% \\
\mathrm{Cl})\end{array}$ & $p$ value & $\begin{array}{l}\text { OR adjusted } \\
\text { for demographic } \\
\text { factors }(99 \% \mathrm{CI})\end{array}$ & $p$ value & $\begin{array}{l}\text { OR adjusted } \\
\text { for demographic } \\
\text { and ICU factors } \\
(99 \% \mathrm{CI})\end{array}$ & $p$ value & $\begin{array}{l}\text { OR adjusted } \\
\text { for demographic, } \\
\text { ICU factors, } \\
\text { and other question- } \\
\text { naires }(99 \% \mathrm{CI})\end{array}$ & $p$ value \\
\hline$E Q-5 D$ & $2.09(1.62-2.69)$ & $<0.001^{*}$ & $2.05(1.56-2.70)$ & $<0.001^{*}$ & $2.20(1.64-2.94)$ & $<0.001^{*}$ & & \\
\hline Barthel index & $1.30(0.97-1.73)$ & 0.019 & $1.22(0.85-1.75)$ & 0.158 & $1.24(0.85-1.82)$ & 0.142 & $0.84(0.42-1.67)$ & 0.512 \\
\hline CFQ & $1.43(0.98-2.07)$ & 0.014 & $1.38(0.94-2.03)$ & 0.031 & $1.40(0.94-2.10)$ & 0.031 & $0.84(0.47-1.50)$ & 0.439 \\
\hline HADS & $2.20(1.60-3.02)$ & $<0.001^{*}$ & $2.04(1.47-2.84)$ & $<0.001^{*}$ & $2.05(1.45-2.89)$ & $<0.001^{*}$ & $2.06(1.18-3.61)$ & $0.001^{*}$ \\
\hline IES & $1.74(1.26-2.40)$ & $<0.001^{*}$ & $1.64(1.17-2.30)$ & $<0.001^{*}$ & $1.57(1.09-2.26)$ & $0.002^{*}$ & $1.13(0.68-1.88)$ & 0.525 \\
\hline
\end{tabular}

Association between (standardized) questionnaire scores and self-reported unacceptable outcome of ICU treatment versus self-reported acceptable plus neutral outcome, expressed as adjusted odds ratios from multivariable logistic regression. Odds ratios are expressed for decreases in EQ-5D index value and Barthel index and for increases in HADS, CFQ, and IES scores. Demographic characteristics: age, gender, and place of residence (home vs. rehabilitation clinic or nursing home). ICU characteristics: type of admission, length of stay, comorbidities, APACHE score, highest SOFA score, and use of CVVH

99\% CI 99\% confidence interval, OR odds ratio, ICU intensive care unit, EQ-5D EuroQoL-5 dimension, HADS hospital anxiety and depression scale, CFQ cognitive failures questionnaire, IES impact of event scale, $C V V H$ continuous venovenous hemofiltration

${ }^{*} p<0.003$ was considered to be significant

1.60-3.02), and on the IES (OR 1.74, 99\% CI 1.26-2.40) and self-reported unacceptable outcome. When adjusted for demographic factors alone or for both demographic and ICU factors, a lower EQ-5D index value, higher HADS score, and higher IES score were significantly associated with a self-reported unacceptable outcome. The Barthel index and CFQ had no effect on self-reported unacceptable outcome in any of the adjusted analyses.

When adjusting for the other components of PICS, along with demographic factors and ICU factors, only the HADS score was significantly associated with selfreported unacceptable outcome of ICU treatment with an OR of 2.06 (99\% CI 1.18-3.61).

\section{Supplementary analyses}

The sensitivity analysis in which self-reported neutral and unacceptable outcome 1 year after ICU were combined and compared to the acceptable outcome group showed the same significant association with the HADS score in the logistic regression analysis (Supplementary Table S1).

In the multinomial regression analysis, neutral and unacceptable responding patients were compared with patients reporting an acceptable outcome (Supplementary Table S2). This analysis showed that the neutral response group differs from both the unacceptable outcome and acceptable outcome group. It also showed a much stronger effect of unfavorable EQ-5D and HADS scores in the unacceptable group compared to neutral responders.

The logistic regression analyses of the association between the EQ-5D domains and unacceptable outcome (Supplementary Table S3) show an association of unfavorable scores in all domains with unacceptable outcome in both unadjusted and adjusted analyses. Impairment in usual activities (OR 2.14, CI 99\% 1.483.09 ) and mood (OR 2.13, CI 99\% 1.62-2.79) had the strongest association with unacceptable outcome.

We were unable to identify a discriminating EQ-5D index value that could define unacceptable outcome of ICU treatment 1 year after discharge (Supplementary Figs. S1 and S2). The area under the ROC curve was 0.706 and for the EQ-5D cutoff value of 0.72 , the sensitivity and specificity were both $69 \%$.

\section{Discussion}

The aim of this study was to investigate the effect of overall HRQoL and of the components of PICS on the risk of a self-reported unacceptable outcome of ICU treatment. We found that a low overall HRQoL corresponds to a self-reported unacceptable outcome, but were unable to identify a cutoff value for the patient-reported outcome measure on overall HRQoL. Considering PICS, symptoms of anxiety and depression have the strongest association with self-reported unacceptable outcome 1 year after ICU discharge.

ICU survivors with a self-reported unacceptable outcome reported lower overall HRQoL index values. Interestingly, the majority of ICU survivors (74\%) rate their health as being acceptable even with low overall HRQoL. In other words, some patients with severe impairments reflected by a low EQ-5D index value report an acceptable outcome. This is illustrated by a great overlap in the distribution of EQ-5D index values between the group with unacceptable and acceptable/neutral outcome. We were therefore unable to identify an EQ-5D cutoff value defining an unacceptable outcome. This 
divergence implies unmeasured factors that impact how patients perceive their outcome in terms of acceptance. One explanation might be the disability paradox [22]. This phenomenon describes patients with severe illness whose appraisal of their quality of life is good or excellent. It indicates that quality of life reflects a balance of body and mind within a social context and environment. Some patients make the decision to live, rather than just to survive, and experience a better HRQoL. Secondly, the discrepancy could reflect the ability to adjust and give meaning to impairments, which has been described previously in ICU survivors [23]. The so-called response shift refers to the change in the meaning of one's self-evaluation of quality of life as a result of changes in internal standards, values, and the conceptualization of quality of life [24-26]. These aspects are not captured in the PROM on HRQoL, impeding straightforward interpretation in survivors of critical illness. From a clinical perspective, an EQ-5D cutoff value for poor ICU outcome should be treated with vigilance, although the association of the HRQoL scores and unacceptable outcome is illustrative $[27,28]$. Studies on ICU outcome should preferably use both objective as well as subjective appraisal of wellbeing [10].

Focusing on the components of PICS, symptoms of anxiety and depression as measured by the HADS were found to be most explanatory for an unacceptable outcome of ICU treatment. This was confirmed by the multivariate analyses and the sensitivity analysis in which the HADS still had a strong effect. Post-traumatic stress disorder symptoms lost their significance after correcting for the other questionnaires, which is likely caused by the fact that the majority of patients who suffer from mental impairments have both symptoms of anxiety and depression, as well as post-traumatic stress [29]. As a result of the known overlap in symptoms of anxiety and depression and the small sample of patients reporting an unacceptable outcome, more detailed analysis of the impact of each was considered unavailing.

Physical impairment, as measured by the Barthel index, was not associated with self-reported unacceptable outcome after ICU treatment. However, more than $70 \%$ of all responding ICU survivors reported a Barthel index score higher than 16 indicating functional independence in most daily life activities (Table 3). It is known that the Barthel index is less likely to measure differences in the higher range, possibly causing an overestimation of physical functioning [30]. The fact that former ICU patients considered physical outcome to be very important stresses the need for more detailed research on the impact of physical sequelae $[7,10,23]$.

Since persistent mental symptoms mostly impacted self-reported unacceptable outcome, strategies to reduce mental sequelae are likely to benefit health acceptance in ICU survivors. ICU diaries, reduced use of sedatives, and early mobilization are proven interventions to decrease mental sequelae [31-33]. In addition, screening patients early after discharge can aid in identifying patients at risk of mental disabilities [34].

However, appraisal of state of health reflects more than the PROMs measure, as illustrated by the wide distribution of overall HRQoL scores in relation to acceptable health status. Since resilience has been found to be inversely related to mental symptoms in ICU survivors, strategies to improve resilience might also be able to benefit state of health acceptance after ICU discharge [35]. Promoting coping skills and mindfulness training are promising interventions; however, trials are still awaited $[36,37]$. The effect of such interventions on decisionmaking relating to continuation of treatment is as yet not evident either.

To our knowledge, this is the first study to test whether it is justified to translate the results of validated questionnaires (PROMs) into acceptable or unacceptable outcome in former ICU patients [15]. We were able to show that a self-reported unacceptable outcome corresponds to a low overall HRQoL and is mainly explained by mental sequelae. One of the strengths of our study is that we were able to include a large number of patients. The fact that subjective well-being was assessed 1 year after discharge from the ICU is a strong feature. Since for most patients a new equilibrium is established after 1 year, the acquired data in this study can be considered legitimate.

This study also has limitations. Firstly, this is a singlecenter study from the Netherlands, which may impede the generalizability of the findings. Secondly, the measurement of the outcome measures took place at only one time point. The EQ-5D is known to vary over time and both under- as overestimation may have occurred. Thirdly, the incidence of cognitive disabilities might be incorrect as a result of the use of patient-reported questionnaires instead of neurocognitive testing [8]. Fourthly, we have categorized the patients who disagreed with the statement that their outcome was acceptable as the unacceptable group. There is, however, a fine difference between not agreeing that the outcome is acceptable and stating that it is unacceptable. Additionally, in the unacceptable group, more patients received help from caregivers with completing the questionnaire than in the neutral/acceptable group ( $46 \%$ vs. $25 \%$ ). It is possible that this reflects more severe disabilities in the unacceptable group. However, it is also possible that caregiver strain influenced the response to the question whether the outcome was acceptable [38]. Fifthly, only survivors being alive 1 year after discharge were questioned. It is conceivable that some patients who had experienced or feared 
an unacceptable outcome were not alive anymore at the time of follow-up, because they had requested withholding or withdrawal of care. Sixthly, despite the result of the sensitivity analysis we may have lost information by pooling the neutral response group with the acceptable outcome group. The multinomial regression analysis showed that the neutral response group differs from both the unacceptable outcome and acceptable outcome group. Seventhly, the rather conservative Bonferroni correction helped us to avoid false positive associations, but we may have missed some true associations. Lastly, the presence of missing values could cause issues. We are not informed on the distribution of missing patients' outcome. Our study could therefore have under- or overestimated the proportion of patients stating their health as unacceptable.

\section{Conclusions}

Although there is a strong association between low overall HRQoL and self-reported unacceptable outcome of ICU treatment, ICU patients with low overall HRQoL may still consider their outcome acceptable. The mental component of PICS, but not the physical and cognitive component, is strongly associated with self-reported unacceptable outcome of ICU treatment 1 year after discharge.

\section{Electronic supplementary material}

The online version of this article (https://doi.org/10.1007/s00134-019-05583-4) contains supplementary material, which is available to authorized users.

\begin{abstract}
Author details
${ }^{1}$ Department of Intensive Care Medicine, University Medical Center Utrecht, Utrecht University, Mail Stop F06.149, P.O. Box 85500, 3508 GA Utrecht, The Netherlands. ${ }^{2}$ Department of Medical Humanities, Julius Center for Health Sciences and Primary Care, University Medical Center Utrecht, Utrecht University, Utrecht, The Netherlands.
\end{abstract}

\section{Compliance with ethical standards}

\section{Conflicts of interest}

On behalf of all authors, the corresponding author states that there is no conflict of interest.

\section{Ethical approval}

The institutional review board of the University Medical Center Utrecht approved the study and waived the need for informed consent (UMC Utrecht IRB 10/006).

\section{Open Access}

This article is distributed under the terms of the Creative Commons Attribution-NonCommercial 4.0 International License (http://creativecommons.org/ licenses/by-nc/4.0/), which permits any noncommercial use, distribution, and reproduction in any medium, provided you give appropriate credit to the original author(s) and the source, provide a link to the Creative Commons license, and indicate if changes were made.

\section{Publisher's Note}

Springer Nature remains neutral with regard to jurisdictional claims in published maps and institutional affiliations.

Received: 19 November 2018 Accepted: 25 February 2019

Published online: 6 March 2019

\section{References}

1. Needham DM, Davidson J, Cohen $\mathrm{H}$ et al (2012) Improving long-term outcomes after discharge from intensive care unit: report from a stakeholders' conference. Crit Care Med 40:502-509. https://doi.org/10.1097/ cCM.0b013e318232da75

2. Jackson JC, Pandharipande PP, Girard TD et al (2014) Depression, posttraumatic stress disorder, and functional disability in survivors of critical illness in the BRAIN-ICU study: a longitudinal cohort study. Lancet Respir Med 2:369-379. https://doi.org/10.1016/S2213-2600(14)70051-7

3. Calvo-Ayala E, Khan BA, Farber MO et al (2013) Interventions to improve the physical function of ICU survivors: a systematic review. Chest 144:1469-1480. https://doi.org/10.1378/chest.13-0779

4. Pandharipande PP, Girard TD, Jackson JC et al (2013) Long-term cognitive impairment after critical illness. N Engl J Med 369:1306-1316. https://doi. org/10.1056/NEJMoa1301372

5. Turnbull AE, Rabiee A, Davis WE et al (2016) Outcome measurement in ICU survivorship research from 1970 to 2013: a scoping review of 425 publications. Crit Care Med 44:1267-1277. https://doi.org/10.1097/ CCM.0000000000001651

6. Dinglas VD, Chessare CM, Davis WE et al (2018) Perspectives of survivors, families and researchers on key outcomes for research in acute respiratory failure. Thorax 73:7-12. https://doi.org/10.1136/thoraxjnl-2017-21023 4

7. Nedergaard HK, Haberlandt T, Reichmann PD et al (2018) Patients' opinions on outcomes following critical illness. Acta Anaesthesiol Scand 62(4):531-539. https://doi.org/10.1111/aas.13058

8. Wolters AE, Slooter AJC, van der Kooi AW, van Dijk D (2013) Cognitive impairment after intensive care unit admission: a systematic review. Intensive Care Med 39:376-386. https://doi.org/10.1007/s0013 4-012-2784-9

9. Dawson J, Doll H, Fitzpatrick R et al (2010) The routine use of patient reported outcome measures in healthcare settings. BMJ 340:C186. https ://doi.org/10.1136/bmj.c186

10. Needham DM, Sepulveda KA, Dinglas VD et al (2017) Core outcome measures for clinical research in acute respiratory failure survivors. an international modified Delphi consensus study. Am J Respir Crit Care Med 196:1122-1130. https://doi.org/10.1164/rccm.201702-03720C

11. Robinson KA, Davis WE, Dinglas VD et al (2017) A systematic review finds limited data on measurement properties of instruments measuring outcomes in adult intensive care unit survivors. J Clin Epidemiol 82:37-46. https://doi.org/10.1016/j.jclinepi.2016.08.014

12. Lim WC, Black N, Lamping D et al (2016) Conceptualizing and measuring health-related quality of life in critical care. J Crit Care 31:183-193. https:// doi.org/10.1016/j.jcrc.2015.10.020

13. König C, Matt B, Kortgen A et al (2019) What matters most to sepsis survivors: a qualitative analysis to identify specific health-related quality of life domains. Qual Life Res 28:637. https://doi.org/10.1007/s1113 6-018-2028-8

14. Griffith DM, Salisbury LG, Lee RJ et al (2018) Determinants of healthrelated quality of life after ICU: importance of patient demographics, previous comorbidity, and severity of illness. Crit Care Med 46:594-601. https://doi.org/10.1097/CCM.0000000000002952

15. Soliman IW (2018) Predicting long-term outcomes of intensive care patients. Chapter five: hidden normativity in categorizations of functional outcomes in intensive care studies. Dissertation, University of Utrecht, the Netherlands

16. Rabin R, Gudex C, Selai C, Herdman M (2014) From translation to version management: a history and review of methods for the cultural 
adaptation of the EuroQol five-dimensional questionnaire. Value Health 17:70-76. https://doi.org/10.1016/j.jval.2013.10.006

17. Szende A, Janssen B, Cabases J (2014) Self-reported population health: an international perspective based on EQ-5D. Springer, Dordrecht. https:// doi.org/10.1007/978-94-007-7596-1

18. Mahoney Fl, Barthel DW (1965) Functional evaluation: the Barthel index. Md State Med J 14:61-65

19. Broadbent DE, Cooper PF, FitzGerald P, Parkes KR (1982) The cognitive failures questionnaire (CFO) and its correlates. Br J Clin Psychol 21(Pt 1):1-16

20. Zigmond AS, Snaith RP (1983) The hospital anxiety and depression scale. Acta Psychiatr Scand 67:361-370

21. Horowitz M, Wilner N, Alvarez W (1979) Impact of event scale: a measure of subjective stress. Psychosom Med 41:209-218

22. Albrecht GL, Devlieger PJ (1999) The disability paradox: high quality of life against all odds. Soc Sci Med 48:977-988

23. Eakin MN, Patel Y, Mendez-Tellez P et al (2017) Patients' outcomes after acute respiratory failure: a qualitative study with the PROMIS framework. Am J Crit Care 26:456-465. https://doi.org/10.4037/ajcc2017834

24. Rapkin BD, Schwartz CE (2004) Toward a theoretical model of qualityof-life appraisal: implications of findings from studies of response shift. Health Qual Life Outcomes 2:14. https://doi.org/10.1186/1477-7525-2-14

25. Hofhuis JGM, van Stel HF, Schrijvers AJP et al (2009) Conceptual issues specifically related to health-related quality of life in critically ill patients. Crit Care 13:118. https://doi.org/10.1186/cc7699

26. Sprangers MA, Schwartz CE (1999) Integrating response shift into health-related quality of life research: a theoretical model. Soc Sci Med 48:1507-1515

27. Soliman IW, de Lange DW, Peelen LM et al (2015) Single-center largecohort study into quality of life in Dutch intensive care unit subgroups, 1 year after admission, using EuroQoL EQ-6D-3L. J Crit Care 30:181-186. https://doi.org/10.1016/j.jcrc.2014.09.009

28. Benoit DD, Jensen HI, Malmgren J et al (2018) Outcome in patients perceived as receiving excessive care across different ethical climates: a prospective study in 68 intensive care units in Europe and the USA. Intensive Care Med 44:1039-1049. https://doi.org/10.1007/s00134-018-5231-8

29. Wolters $A E$, Peelen LM, Welling MC et al (2016) Long-term mental health problems after delirium in the ICU. Crit Care Med 44:1808-1813. https:// doi.org/10.1097/CCM.0000000000001861
30. Prodinger B, O'Connor RJ, Stucki G, Tennant A (2017) Establishing score equivalence of the functional independence measure motor scale and the Barthel index, utilising the international classification of functioning disability and health and Rasch measurement theory. J Rehabil Med 49:416-422

31. Eggmann S, Verra ML, Luder G et al (2018) Effects of early, combined endurance and resistance training in mechanically ventilated, critically ill patients: a randomised controlled trial. PLoS One 13:e0207428. https:// doi.org/10.1371/journal.pone.0207428

32. Strøm T, Martinussen T, Toft P (2010) A protocol of no sedation for critically ill patients receiving mechanical ventilation: a randomised trial. Lancet 375:475-480. https://doi.org/10.1016/S0140-6736(09)62072-9

33. Jones C, Backman C, Capuzzo M, Egerod I (2010) Intensive care diaries reduce new onset post traumatic stress disorder following critical illness: a randomised, controlled trial. Crit Care 14(5):R168. https://doi. org/10.1186/cc9260

34. Milton A, Brück E, Schandl A et al (2017) Early psychological screening of intensive care unit survivors: a prospective cohort study. Crit Care 21:273. https://doi.org/10.1186/s13054-017-1813-z

35. Maley JH, Brewster I, Mayoral I et al (2016) Resilience in survivors of critical illness in the context of the survivors' experience and recovery. Ann Am Thorac Soc 13:1351-1360. https://doi.org/10.1513/AnnalsATS.20151 $1-782 \mathrm{OC}$

36. Cox CE, Porter LS, Buck PJ et al (2014) Development and preliminary evaluation of a telephone-based mindfulness training intervention for survivors of critical illness. Ann Am Thorac Soc 11:173-181. https://doi. org/10.1513/AnnalsATS.201308-2830C

37. Cox CE, Porter LS, Hough CL et al (2012) Development and preliminary evaluation of a telephone-based coping skills training intervention for survivors of acute lung injury and their informal caregivers. Intensive Care Med 38:1289-1297. https://doi.org/10.1007/s00134-012-2567-3

38. Sneeuw KCA, Sprangers MAG, Aaronson NK (2002) The role of health care providers and significant others in evaluating the quality of life of patients with chronic disease. J Clin Epidemiol 55:1130-1143 